\title{
Psychological Loneliness And Its Relationship To Death Anxiety In The Elderly
}

\author{
Assistant Professor Dr. Abdulkarim Obaid Jumaa \\ Department of Educational and Psychological Sciences/College of Education for Humanities / University of \\ Anbar
}

Article History: Received:11 January 2021; Accepted: 27 February 2021; Published online: 5 April 2021

\begin{abstract}
The current paper aims to identify the level of psychological unit among the elderly, to identify the level of psychological anxiety in the elderly, to identify the nature of the correlation between psychological loneliness and death anxiety, and to identify the extent of the psychological unit's contribution to death anxiety. There are (180) elderly people. In order to achieve the objectives of the study, the researcher constructed, designed, and then applied the measures of psychological unit and death anxiety, and the results showed the following:

1- The level of psychological loneliness and death anxiety of the research sample is high in all dimensions.

2 - There is a positive significant correlation between psychological loneliness and death anxiety.

3 - The psychological unit, with its three dimensions, shares the ability to predict the anxiety of death.
\end{abstract}

Key words: psychological loneliness, death anxiety, the elderly.

\section{Introduction:}

The World Health Organization (WHO, 2017) estimates that the proportion of the elderly in the world will double from about $12 \%$ to $22 \%$ between 2015 and 2050. This means an expected increase from 900 million to two billion people over the age of 60 . The figures also indicate that the fastest growing social strata are those of 65 years of age or older. It is also expected that the number of elderly people aged 65 years or over who live alone will increase globally, as nearly $28 \%$ (14.3 million). Older Americans live alone, and they face health challenges - physical and psychological - in particular, that should be recognized. They are also more likely to suffer from feelings of sadness and mourning, or a decline in socioeconomic status under retirement, or disability. All of these factors can lead to isolation, loss of independence, loneliness, and psychological distress, and more than $20 \%$ of those over the age of 60 suffer from a psychological or neurological disorder, at the same time there is a lack of recognition of mental health problems by specialists. In the field of health care and by the elderly themselves, the stigma surrounding mental disorders makes people hesitant to seek help. (Who, 2017), according to a report (Eurostat, 2015): As of January 1, 2014, there were approximately 94 million people aged 65 and over in the European Union.

Iraq will also face a significant increase in the number of elderly people, as the number of elderly people in 2018 reached one million and 200 thousand people, representing a rate of 3\%. Year 2030. (Ministry of Planning, Iraq)

In addition to that concerns related to the increase of their health, psychological and social problems, especially since the social, political, security, economic and health conditions that the Iraqi society has been experiencing for many decades lead to cultural, social and value changes that have impacted on all its groups in general and on the elderly in particular and have greatly increased their suffering and problems, due to Continuous exposure to traumatic experiences resulting from wars, fighting, threats, and continuous crises that leave their psychological and health effects and appear in multiple forms of disturbances, including a feeling of psychological loneliness, which forces interested scientists and researchers to conduct studies and research dealing with the conditions of the elderly, and urge attention to their affairs in order to understand the nature of the stage The problems they live in, and the problems they suffer from, and of course, mental health problems that are among the most prominent features of this stage, foremost of which is the problem of social withdrawal, feelings of psychological loneliness and death anxiety, and the multiple health and psychological problems that accompany them, which makes the elderly feel that he has become far from others and that the His relationships with others are superficial, helpless, and possibly ostracized.

Feeling of psychological loneliness and death anxiety are two of the important problems in the lives of individuals, because they constitute the starting point for many of the following problems that appear in the life of the individual and society. This cost is current, for example, a study conducted in the United Kingdom in 2017 to estimate the total cost incurred by employers in the United Kingdom, from absenteeism from work and health care and poor or interrupted productivity, due to the feeling of psychological loneliness that their employees suffer at an amount of 2.5 billion pounds annually. (New Economics Foundation \& The Co-Op, 2017).

Also, death anxiety is a common anxiety in all societies, cultures, and ages in general, and at the same time there are few studies that have studied death anxiety in the elderly and the variables associated with it, whose results vary about the nature of its association with these variables, as these studies indicated that levels of anxiety are 
from Death among the elderly changes according to many variables, including: the place of living, lifestyles, and the experiences and experiences that the elderly went through during their lives. Many factors influence death anxiety, such as age, gender, culture, religiosity, physical health and mental health.

\section{Research problem :}

The research problem is trying to study some of the psychological characteristics of the elderly and some psychological problems that they suffer from, especially the feeling of psychological loneliness and death anxiety, as individuals who feel psychologically lonely suffer from the negative feelings of others such as: rejection, exclusion, forgetfulness, abandonment, ignorance, unwanted or not necessary .

The researcher felt this problem through his numerous encounters with the elderly, his interaction and his participation with them, and by virtue of specialization, some of them were expressing feelings of loneliness that he suffers from as well as death anxiety, in addition to the lack of information and the different results of studies and interpretations and their variation on the topic, which raised a great challenge that prompted him to try to get to know On the level of their suffering.

Therefore, the current research problem focuses on identifying the level of psychological unit, the level of death anxiety, the nature of the relationship between them, and the extent of the psychological unit's contribution to death anxiety, which can be formulated with the following questions:

1 / What is the level of psychological loneliness among the elderly?

2 / What is the level of death anxiety in the elderly?

3 / What is the nature of the correlation between psychological loneliness and death anxiety in the elderly?

The importance of the research: The importance of the current research is evidenced by the following points:

1. The importance of the current research is evident in the importance of the research community and its sample of elderly people, because of its social, human and moral standing. The importance is also evidenced by being one of the few studies that will address the study of psychological aspects of an important and basic segment of society, namely the elderly segment that has not Their psychological and behavioral characteristics through research and attention by researchers, and that studying their psychological and behavioral characteristics, and identifying their personal problems and suffering, is a necessary and important matter.

2. Being - as far as the researcher knows - the first research to study the relationship between psychological loneliness and death anxiety in the elderly, and it is a renewed topic. It is certain that every research conducted will provide a realistic field analysis related to the conditions experienced by the elderly.

3. The current research addresses the extent of the psychological unit's contribution to death anxiety in the elderly, and this represents an advanced step that gives us more indications than just studying the correlation they have. Especially since the level of psychological loneliness as a predictor of psychological problems faced by the elderly did not receive much attention by researchers.

4. The research's contribution, through its results, to alerting the need to pay attention to extension and treatment programs for this important segment, especially with regard to the current research problem.

Research objectives: The current research aims to:

1 - Knowing the level of psychological unit among the elderly.

2 - Knowing the level of death anxiety in the elderly.

3 - Identify the nature of the correlation between psychological loneliness and death anxiety in the elderly.

4 - Identify the extent of the psychological unit's contribution to death anxiety.

Defining terms: The researcher will define the following terms:

Psychological unit: Loneliness

Tarröckach (2004, Rokach): it is a subjective-experience that an individual may suffer in spite of his presence with other people when his life is devoid of social relations saturated with intimacy and affection.

Death anxiety

Tumblr (Timbler, 1970) defined it: it is an unpleasant emotional experience revolving around death and related issues, and this experience may precipitate the death of the individual himself.

Theoretical framework :

First / Psychological unit: Loneliness

The feeling of psychological loneliness is a painful experience of the individual that occurs when this individual evaluates his social relationships as abnormal or as few or weak and devoid of familiarity, interaction and harmony, and the experience of feeling psychological loneliness is highly subjective, as the individual can not be alone without feeling psychological loneliness, He can feel alone even though he is living with other people.

As Rokach (1988) sees that psychological loneliness is a source of feelings of psychological and social distress, suffering, isolation, and weakness of motivation and vitality, and that the feeling of psychological loneliness is a painful feeling, and the result of a subjective experience from the severity of sensitivity, and the individual's feeling that he is unwanted and separated from others, and that this feeling is the result of About the perceived absence of saturated social relations, a feeling accompanied by symptoms of psychological stress. Ruckach believes that (Lonely) and (Alone) are two terms derived from the same English word (Allone), but they are not 
synonymous, so it is possible for a person to be alone (Lonely) without being alone By himself, it is also possible for a person to be alone by himself (Alone) and not feel psychological loneliness because aloneness, which means distance from others, family and friends, differs from the psychological loneliness (loneliness) that the individual suffers from even if it is between his family and friends. Rokach, 1988, 543)

Zilboorg (1938) was the first to analyze, using a scientific method, the feeling of psychological loneliness, as he distinguished between lonesome and loneliness, and he believed that psychological loneliness is related to childhood experiences, and loneliness is also distinguished from many quantitative measures of social isolation such as living alone and social status And the number of relationships. For example, it is possible for people who live alone to not feel lonely, while some who are married or who live with others will still experience loneliness. Loneliness can be interpreted as the contradiction between desired and actual relationships. Some researchers believe that the concept of psychological unity and the concept of social isolation are two similar concepts on the basis that the outcome at the end of the matter is one.

Peplau \& Perlman (1982) also views social isolation as a state of minimal contact with others. It differs from loneliness, which is a subjective state of negative feelings about a lower level of social contact than is desired (Peplau \& Perlman 1982,8).

From this point of view it appears that the feeling of loneliness is a painful psychological feeling that includes many types of suffering.

Eric Fromm (2009) studied the causes of loneliness and proved the fact that it is a self-awareness that led the individual to perceive himself as an individual entity that differs from other people. He also pointed out to me that the feeling of loneliness is derived from a series of unsatisfactory social relationships with others of great importance to them (From 2009)., 211).

Carl Rogers (1980) dealt with the subject of psychological unity and the feeling of emptiness from the point of view of human psychology. If his analysis is based on the theory of the self, the concept of the true self and the ideal self, then he explains psychological unity first: as the alienation of the person from himself, or the alienation of the personality from his true inner feelings That is, when the true self is not manifested and rejected by others, or the way others see this self. Second: The contemporary man feels psychological loneliness because he lacks the true human relationships through which he can communicate his true experiences or the true self to other people, He adds that we feel lonely because there is no real human contact with others (Carl Rogers, 1980, p167)

This is in line with other research that highlights the strong relationship between loneliness, social anxiety and depression (Lim, et al, 2016), and in a study (Shazly, 2001) it was shown that the psychological problem most prevalent among the elderly is the feeling of psychological loneliness.

Lester (1967) also sees that people who are in poor mental health view death anxiety in a positive light, and that the elderly fear death to a lesser degree as long as they are in good health, while the elderly who have few activities to occupy their spare time were more Worried about death; And that death anxiety is less among people who live in nursing homes. (Zawout and Qureshi, 2013, 63)

Second / Death anxiety

Death anxiety is one of the basic types of anxiety that is widespread among individuals, and it is defined as unusual and severe anxiety, meaning that it is associated with fear and anxiety when thinking about the dying process or post-death events and is spread among the elderly because they suffer or are susceptible to various physical problems, chronic conditions, and weakness In movement, physical disabilities, greater dependence on others, and significant losses (for example, spouse, friends, peers, retirement) that lead to feeling

Sigmund Freund (1915) was one of the first to talk about death anxiety, and he saw that there is an unconscious belief among individuals in the issue of immortality, meaning the absence of death, and therefore the death anxiety felt by individuals is nothing but an expression of struggles suppressed in childhood that have not been resolved or resolved. They can deal with it or express feelings towards it. (Freud, 1981, 31)

Erik Erikson (1963) believes that the last stage of psychosocial development, individuals experiences what he called ego integration, so the individual reviews and evaluates his past life, either despair, a sense of failure and inferiority due to the passage of life without a goal or any meaningful achievements, then death awaits as if A ghost haunts him and frightens him, (symptoms of death anxiety). As for the integration of ego, it gives the individual a sense of contentment and accepts what is to come. To the level of ego integration because when they look at their life, they find meaning in their life, and thus they have a goal to continue life, (Lange, 1997). Ernst Becker (1973), an anthropologist who provided profound existential explanations for death anxiety, believes that it is a deep source of existential anxiety about death, which is the belief that everything stops after death, which generates various fears in daily life, and that individuals derive their protection from anxiety. Death by giving meaning to their lives and thus enhancing self-concept and self-esteem (Becker, 1973,218)

Tumblr (Timbler, 1970) is one of the first researchers who touched upon the definition of the concept of death anxiety, through his study, which was represented by building a tool about the relationship of death with the deterioration of the psychological state of the person on the verge of death, and Tumblr believes that death 
anxiety is a major source of anxiety. (Timbler) (1970, p165), and (Milan Klein) believes that the study of death anxiety is of great importance as it forms the basis for all kinds of anxiety. (Templer, 1979, 25),

In the study (Al-Qiq, 2016), which was titled Death Anxiety and its Relation to Mental Health in a Sample of Elderly People, and to achieve the objectives of the research, the researcher prepared the Elderly People's Death Anxiety Scale and the Elderly Mental Health Scale. (65.63\%), and it was also high for all dimensions of the death anxiety scale (Al-Qiq, 2016, p.73)

The study (Mahmoud, 2015) entitled death anxiety in the elderly and its relationship to satisfaction with life goals, as the researcher prepared a measure of death anxiety and a measure of satisfaction with life goals for retirees, and after applying them, the results showed that the level of death anxiety was low among the elderly, and that the level of satisfaction with the goals Life is high. And that the relationship between them was negative, as the correlation coefficient reached (-0.133). (Mahmoud, 2015, 373)

Research methodology and procedures:

For the purpose of achieving the research objectives, the researcher took the following actions:

First: the research community and its sample:

The current research community is determined by the elderly aged (65) years or more than the residents of Ramadi for the year 2021, whose numbers reached $(39,476)$ thousand according to the latest statistics. (Ministry of Planning, 2018)

The research sample :

A deliberate sample of (180) elderly males was chosen due to the difficulty of obtaining elderly females who frequent the four pension and social care payroll offices in Ramadi and those aged (65) years and over, as shown in Table (1)

Table (1) Distribution of the individuals of the current research sample according to age groups

\begin{tabular}{|c|c|c|}
\hline ratio & No. & Age groups \\
\hline$\% 62$ & 112 & $69-65$ \\
\hline$\% 25$ & 46 & $74-70$ \\
\hline$\% 8.8$ & 16 & $79-75$ \\
\hline$\% 3.3$ & 6 & 80 or more \\
\hline$\% 100$ & 180 & Total \\
\hline
\end{tabular}

Second: the two search tools:

In order to measure the research variables, psychological loneliness and death anxiety, and to achieve the objectives of the current research, and after reviewing a set of relevant Iraqi, Arab and foreign standards, and studying the aspects that measure them, and they could be suitable for application to the current research sample, the researcher decided to build the two research tools in the Iraqi environment, They correspond to the nature of the current research sample and its variables, and through them, the objectives of the current research can be achieved, as follows:

First - Psychological Unit Scale:

To build the scale, the researcher took the following steps: Determining the theoretical definition of the variable, then determining its content or fields and their definitions because it is the basis for the method by which the content of the paragraphs is formulated, so that the group of paragraphs represents the content of each area that has been identified and approved. Elements of) the feeling of psychological loneliness. Rokach (1988) believes that there are four dimensions or basic components of psychological loneliness, as Weiss (1987) defined three dimensions of psychological loneliness, and also (Ditommaso \& Spinner, 1993) identified three areas of the scale of loneliness. Mental. Based on the literature and previous measures, three basic dimensions (domains) were identified for the scale and their definitions, and the domains are: (social disability, loss of affection, feeling of rejection)

Drafting the scale paragraphs: The scale paragraphs were formulated after the researcher examined the studies, literature and standards related to the subject of psychological unity, as well as the Arab and foreign references, so the number of paragraphs reached (42) paragraphs distributed into three areas, before which five alternatives were placed (always, often, Sometimes, rarely, ever), it takes marks for correction $(5,4,3,2,1)$.

Validity of scale paragraphs: The researcher presented the scale paragraphs to (10) expert referees specialized in the field of educational and psychological sciences. In light of their observations, some paragraphs were formulated and (4) paragraphs were excluded because their value calculated using Ka 2 is less than the tabular value of (3.84) At the level of significance (0.05) and the degree of freedom (1).

Scale Instructions: The scale instructions are considered as a guide for answering its paragraphs, so the instructions were formulated clearly and accurately, and the subject was asked to answer the paragraphs frankly for the purposes of scientific research, and that the answer would not be seen by anyone except the researcher to assure the subject of the confidentiality of his response.

Exploratory application: The aim of this step is to identify the extent of clarity of the scale paragraphs, the effectiveness of the alternatives to the answer, the clarity of the instructions and the method of response, the 
knowledge of the time required for the answer, and other aspects in order to avoid them before the final application, and to achieve this, the researcher chose a random sample of (25) elderly from The research community, and it was found that the paragraphs and instructions of the scale are clear, and that the average time taken to answer is: (15) minutes.

Paragraph analysis:

A - The method of the two extremes: (Contrasted group)

The researcher distributed the research form to the research sample of (180) elderly people, with the aim of achieving the psychometric properties of the scale prepared in the current research, and accordingly, the number of questionnaires that were subjected to analysis in the manner of the two extremes was (96) questionnaires, (48) for the upper group and (48) for the lower group. After analyzing the scale items using the T-test for two independent samples (t-test) to test the differences between the upper and lower groups, for each paragraph of the current scale of 38 paragraphs, the calculated $\mathrm{T}$ value for each paragraph was compared with the tabular $\mathrm{T}$ value, and it was found that the paragraphs of the scale domains, It was a function at the level of significance (0.05).

B. Relation of paragraph score to overall score (Internal consistency): Internal consistency Method

This method is based on finding the correlation between the degree of each paragraph with the total degree of the scale (Nannally, 1978, 262) or the total degree of the sub-scale (field) to which it belongs, and the researcher used the correlation coefficient (Pearson) to extract the correlation between the degree of each paragraph with The total score of the sub-scale to which it belongs, for the scale building sample of (180) elderly, amounting to (38) items distributed on the scale domains, and the correlation coefficients for all paragraphs of the psychological unit scale appeared to be statistically significant at (0.01) level.

Stability: Cronbach's Alpha equation was used to calculate the stability of the psychological unit scale, as this method is based on the calculation of internal consistency (Nunnally, 1970,126). 0.82) This is a good stability coefficient and the scale is characterized by internal consistency (Cronbach, 1970.63).

Second - a measure of death anxiety:

In order to build a measure of death anxiety in the current research, the standards and literature related to the subject were reviewed, such as the Donald Tumbler scale (Timbler, 1970Donald) and the scale (Abdul-Khaleq, 1996). Therefore, a theoretical definition of death anxiety was developed, and then three areas of the current scale and their definitions were identified. The domains are: the field of continuous thinking about death, the domain of the domination of the thought of death (dominates, death), and the field of repetition, idea, death.

Paragraph Formulation:

As a result of the previous procedures, it was possible to collect (33) paragraphs, distributed into three domains (sub-measures). It was taken into account in their formulation that they be easy, direct and expressive of one idea, and their number is not many because they will be presented to the elderly, and five alternatives have been developed for the answer, which are: (always) Often, sometimes, a little, rarely), and the paragraphs are given grades upon correction $(5,4,3,2,1)$, because all the paragraphs are of one positive direction.

Validity of paragraphs: To verify this, the paragraphs of each field and their theoretical definition of the three fields were placed in a special form, and they were asked: to judge the validity of the paragraphs, the validity of the field to which each paragraph belongs, and any other observations or additions, and after collecting the expert forms and analyzing them statistically, they were excluded (3 Paragraphs, which are the paragraphs whose values using the chi-square (Ka-2) were less than (3.84) at a level of significance (0.05) and with a degree of freedom of one, and the wording of some paragraphs was modified, and thus the scale consisted of (30) items.

Exploratory application of the scale: In order to achieve this step, the researcher prepared the instructions for answering the scale, as the aim of this step was to identify the extent of clarity of the scale paragraphs, the effectiveness of the answer alternatives, the clarity of the instructions and the method of response, the knowledge of the time required to answer, and other aspects in order to avoid them before The final application, and to achieve this, the researcher chose a random sample of (25) elderly people, and it was found that the paragraphs of the scale and its instructions are clear, and that the average time taken to answer is: (15) minutes. Paragraphs analysis: The death anxiety scale prepared in the current research was applied to the sample of 180 elderly members and corrected the answer forms. To extract the discriminatory strength of the paragraphs, the sample individuals 'scores were ranked from the highest overall score to the lowest overall score, and the two extreme groups were identified at a rate of (27\%) of All adult group (48). After the scale paragraphs were analyzed by using the T-test for two independent samples (t-test) to test the differences between the two extreme groups, the $\mathrm{T}$ value calculated for each item was compared with the tabular $\mathrm{T}$ value, and it was found that the scale's (30) items were significant at a level of significance (0.05). .

Internal consistency of paragraphs (truthfulness): The researcher calculated the internal consistency of paragraphs through the following steps:

a. The relationship of the paragraph to the total score: In calculating the validity of each paragraph, the researcher relied on the Person correlation coefficient between the scores of each paragraph and the total score, 
because the scores of the paragraph are continuous and graded (Dubois, 1962,144), noting that the paragraph validation sample consists of (180). Individuals.

B. Correlation of paragraphs with the domain to which they belong: For the purpose of calculating the value of the correlation coefficient between the paragraph degree and the total degree of the field to which they belong, Pearson correlation coefficient was used, and it was found that all the correlation coefficients are statistically significant at a level of significance (0.05) and with a degree of freedom (178) and that its critical value is equal to $(0.087)$.

C. The relationship of the domains with each other and their relationship to the total degree: The internal correlation coefficients were found between the total scores of the domains and the total degree of the scale to achieve this, the Pearson correlation coefficient between the scores of the three subdomains was used to arrive at the internal correlations matrix, and it was found that all the correlation coefficients are statistically significant at a level of significance (0.05) As the values of the correlation coefficients were greater than the critical value of (0.087) with a degree of freedom (178) and the level of significance (0.05).

Stability: To calculate the stability of the death anxiety scale prepared in the current research, the Cronbach alpha equation was also used for all scores of the sample members of (180) individuals, so the internal consistency coefficient was (0.79) and this coefficient is good, which indicates the stability of the scale.

Research results and their interpretation:

First - Knowing the level of psychological unit in the elderly:

To verify the first goal of the research, the responses of the research sample were calculated on the psychological unit scale of (180) elderly people, so the average of the sample responses was (123) with a standard deviation of (11.24), and by comparing this average with the hypothetical average of the scale of (114) using the T-test. For a sample and a population, it appeared that there is a difference between the two averages and in favor of the mean of the research sample, and as shown in Table (2)

Table (2) T-test for a sample of the elderly on the scale of psychological unit and its fields

\begin{tabular}{|c|c|c|c|c|c|c|}
\hline \multirow{2}{*}{$\begin{array}{l}\text { sign } \\
(0,05)\end{array}$} & \multicolumn{2}{|c|}{$\mathrm{T}$ value } & \multirow{2}{*}{$\begin{array}{l}\text { Hypothesized } \\
\text { mean }\end{array}$} & \multirow{2}{*}{$\begin{array}{c}\text { standard } \\
\text { deviation }\end{array}$} & \multirow{2}{*}{ SMA } & \multirow{2}{*}{$\begin{array}{c}\text { fields } \\
\text { Psychological unit }\end{array}$} \\
\hline & Tabular & Calculated & & & & \\
\hline sign & 1,96 & 14.18 & 42 & 8.96 & 51 & Social impotence \\
\hline sign & 1,96 & 8.46 & 36 & 10.93 & 42 & Loss of familiarity \\
\hline sign & 1,96 & 6.71 & 36 & 8.67 & 40 & Feeling rejected \\
\hline sign & 1,96 & 16.69 & 114 & 14.38 & 131 & $\begin{array}{c}\text { The scale as a } \\
\text { whole }\end{array}$ \\
\hline
\end{tabular}

Table (2) shows that the calculated $\mathrm{T}$ value for the psychological unit scale and its fields is greater than the tabular value of (1.96), and this indicates that the average of the elderly sample on the psychological unit scale and its fields is higher than the hypothetical averages, meaning that the level of psychological unit of the current research sample is level High, which reflects the heightened sense of their psychological loneliness with all its components.

Second - Knowing the level of death anxiety in the elderly:

To identify this goal, the researcher calculated the scores of the answers of the individuals of the research sample of (180) elderly on the scale of death anxiety prepared in the current research. The arithmetic mean was extracted and reached (106) and the standard deviation (10.78) for the scores of the research sample, and when this average was compared with the hypothetical average, the result was as shown in Table (3)

Table (3) T-test for a sample of the elderly on the death anxiety scale and its fields

\begin{tabular}{|c|c|c|c|c|c|c|}
\hline \multirow{2}{*}{$\begin{array}{c}\text { sign } \\
(0,05)\end{array}$} & Tabular & Calculated & \multirow{2}{|c|}{$\begin{array}{c}\text { Hypothesized } \\
\text { mean }\end{array}$} & $\begin{array}{c}\text { standard } \\
\text { deviation }\end{array}$ & SMA & $\begin{array}{c}\text { fields } \\
\text { Death anxiety }\end{array}$ \\
\cline { 2 - 7 } sign & 1,96 & 8.35 & 30 & 7.11 & 34 & $\begin{array}{c}\text { Constant thinking } \\
\text { about death }\end{array}$ \\
\hline sign & 1,96 & 6.35 & 30 & 7.36 & 33 & $\begin{array}{c}\text { The control of the } \\
\text { idea of death }\end{array}$ \\
\hline
\end{tabular}




\begin{tabular}{|c|c|c|c|c|c|c|}
\hline sign & 1,96 & 11.70 & 30 & 7.42 & 36 & $\begin{array}{c}\text { Repeating the idea } \\
\text { of death }\end{array}$ \\
\hline sign & 1,96 & 15.35 & 90 & 18.92 & 111 & $\begin{array}{c}\text { The scale as a } \\
\text { whole }\end{array}$ \\
\hline
\end{tabular}

It is evident from Table (3) that the average scores and ranges of death anxiety among the members of the current research sample are higher than the hypothesis averages score of the scale with a significance level $(0.05)$, and this means that there is a statistically significant difference between the average of the elderly sample, and the hypothesis averages in favor of the research sample, meaning that Elderly individuals of the current research sample have a level of death anxiety in all its dimensions and with a higher than average degree.

Third - To recognize the nature of the correlation between psychological loneliness and death anxiety in the elderly:

To identify the nature of the correlation between psychological loneliness and death anxiety in the elderly, the researcher used the Pearson correlation coefficient for the scores of the sample members in each field and their scores on the test wisdom scale, so the results were as shown in Table (4).

Table (4) Correlation coefficient and T-value between psychological unit and death anxiety

\begin{tabular}{|c|c|c|c|c|c|}
\hline $\begin{array}{c}\text { sign } \\
\text { level } \\
(0,05)\end{array}$ & Tabular & Calculated & $\begin{array}{c}\text { The value of the correlation } \\
\text { coefficient between the } \\
\text { domains of psychological } \\
\text { unity and death anxiety }\end{array}$ & sample & $\begin{array}{c}\text { Areas of } \\
\text { psychological unit }\end{array}$ \\
\hline sign & 1,96 & 8,943 & 0,491 & 180 & Social impotence \\
\hline sign & 1,96 & 7,103 & 0,389 & 180 & Loss of familiarity \\
\hline sign & 1,96 & 6,542 & 0,369 & 180 & Feeling rejected \\
\hline sign & 1,96 & 11,241 & 0,587 & 180 & $\begin{array}{c}\text { The scale as a } \\
\text { whole }\end{array}$ \\
\hline
\end{tabular}

It is evident from Table (4) that the relationship between the field of social disability and death anxiety is a direct, significant relationship in the sense that the greater the individual's social disability, the greater the death anxiety he has, and that the relationship between the field of loss of familiarity and death anxiety is a direct relationship indicating that the greater the loss of affection for the individual the greater the anxiety of death $\mathrm{He}$ has, and that the relationship between the domain of feelings of rejection and anxiety of death is a direct, significant relationship in the sense that the greater the feeling of rejection of the elderly, the greater the anxiety of death he has, and that the relationship between the field of affirmative knowledge and experiential wisdom is a direct, indicative relationship in the sense of the greater the assured knowledge of the individual, the more empirical wisdom he has

Fourth - To identify the extent of the psychological unit's contribution to explaining the variation in death anxiety in the elderly:

To achieve this goal, the researcher used a simple linear regression analysis to find out the extent of the contribution of the independent variable (the psychological unit) in explaining the apparent variation in the predicted dependent variable (death anxiety), and it became clear that the determination coefficient reached $(0.389)$ and the square of the determination coefficient (R2), i.e. the ratio of variance. The interpreter reached (0.151). The value of the coefficient of determination (R2) indicates the quality of the regression analysis model in forecasting, and indicates that the independent variable explains approximately $15.1 \%$ of the total variance of the degree of cognitive bias and when the determination factor was subjected to regression analysis, the F-ratio was a function at the level (0.05) at the degrees of freedom (1) and (178), and Table (5) illustrates this.

Table (5) The FAT ratio for the simple regression analysis of the degree of the independent variable (abstract thinking) with the dependent variable cognitive bias

\begin{tabular}{|c|c|c|c|c|c|c||}
\hline \multirow{2}{*}{ sign level } & \multicolumn{2}{|c|}{ F value } & \multirow{2}{*}{$\begin{array}{c}\text { Average of } \\
\text { squares }\end{array}$} & $\begin{array}{c}\text { Degree of } \\
\text { free }\end{array}$ & Sum of squares & $\begin{array}{c}\text { The source } \\
\text { of the } \\
\text { contrast }\end{array}$ \\
\cline { 2 - 7 } & Tabular & Calculated & & 1 & 1926.709 & Regression \\
\hline \multirow{2}{*}{0,05} & \multirow{2}{*}{3,92} & \multirow{2}{*}{31,726} & 1926.709 & 178 & 10809.935 & Residual \\
\cline { 5 - 7 } & & & 60.730 & 179 & 13227,221 & Macro \\
\hline
\end{tabular}

It can be seen from Table (5) that the value of the F-ratio calculated for the analysis of the variance of the regression is greater than the value of the tabular F-ratio of (3.92) at the level of significance (0.05) and with degrees of freedom (1) and (93), and this indicates that the thinking variable Abstract has an effect on the 
variability of the cognitive bias variable among university students. Through the values of the regression coefficient (Beta), the standard error, and the values of the relative contribution of (Beta) standard, through which the significance of the independent variable in the dependent variable can be known. Table (6) illustrates this.

Table (6) the values of the beta parameter and the standard error of the independent variable in the total variance of the cognitive bias variable in the research sample

\begin{tabular}{|c|c|c|c|c|c|c|}
\hline \multirow{2}{*}{$\begin{array}{c}\text { sign } \\
\text { level } \\
\mathbf{0 , 0 5}\end{array}$} & Tabular & Calculated & $\begin{array}{c}\text { Toefficient } \\
\text { (Beta) } \\
\text { Standard }\end{array}$ & $\begin{array}{c}\text { Standard } \\
\text { error }\end{array}$ & $\begin{array}{c}\text { Beta } \\
\text { coefficient } \\
\text { (B) }\end{array}$ & variable \\
\hline sign & 1,98 & 4.882 & - & 11.092 & 54.155 & Fixed limit \\
\hline sign & 1,98 & 5.633 & 0.389 & 0.86 & 0.486 & $\begin{array}{c}\text { Psychological } \\
\text { unit }\end{array}$ \\
\hline
\end{tabular}

The following is clear from the table above:

Fixed term: The result indicates that the value of (B) reached (54.155) degrees, and the calculated $\mathrm{T}$ value for it reached (4.882), which is greater than the tabular value of (1.98) at the level of significance (0.05), and this indicates the existence of Other variables related to cognitive bias in the research sample that were not covered by the current research.

The effect of (psychological unity) in explaining the variance in death anxiety among the research sample is equal to (0.389), and it is reflected by the (Beta) square, which equals $(0.151)$, meaning that $(15.1 \%)$ of the variance in death anxiety among the research sample is due to the effect of unity. Psychological, which is statistically significant at the level of (0.05), as the calculated $\mathrm{T}$ value (5.633) was greater than the tabular $\mathrm{T}$ value (1.98).

Conclusions:

The elderly members of the current research sample suffer from a feeling of psychological loneliness in its three dimensions (social impotence, loss of familiarity, and a feeling of rejection), according to the results of the T-test and at a level of significance at the level of (0.05). The researcher believes that this result is logical to a large extent, especially since the current research sample is of old age, as the aging stage in itself is a challenging stage with all its requirements, and a stage in which the feeling of psychological loneliness increases, in addition to what they were subjected to in terms of pressures and bad differential events such as the loss of people Close associates, retirement, and others around him, the deterioration of his physical health, which reflects on him and his outlook on life and others, and paves the way for the emergence of difficulties and health and psychological problems, the most prominent of which is anxiety of all kinds.

So when the elderly look at their current life with all its disturbances, they are afraid of the unknown future. In addition, studies have indicated that the elderly face great challenges as they deal with the variables of civilized and technological progress and modern means of communication and the negative aspects and phenomena they have produced and psychological pressures that make them more vulnerable to a feeling of psychological loneliness, as well as On the other biological, personal and social causes, and this finding is consistent with a study

While the study (Saadi and Bekdash, 2017) found that the level of psychological loneliness among the sample of elderly people residing in care homes is average, and this result is consistent with the study (Bekhet 2012), which confirmed that the elderly suffer from psychological loneliness at an average level, and that $40 \%$ Of the elderly feel lonely and isolated. (Saadi and Bekdash, 2017, 365), as well as a study (Iman, 2015) concluded that the level of psychological loneliness among the elderly was average, as it reached the arithmetic mean (42.52), which indicates the average level (Iman, 2015, 84)

The results of the current research also showed that the elderly research sample suffers from death anxiety in all its dimensions: (constant thinking of death, control of the idea of death, repetition of the idea of death), and this result is consistent with what many studies have indicated, such as a study (Mukhtar and Shaanabi, 2017) that It indicated that the degree of death anxiety among the sample members was high $(76.41 \%)$ (Mukhtar, Shaanabi, 2017, 182) and a study (Maamaria and Khazar, 2009) confirmed that death anxiety among elderly males is high (Ma'amariah and Khazar, 2009, 81). ), And a study (Nusseibeh, 2017) indicated that the elderly suffer from death anxiety, and this is due to the obsessive thoughts they think about the direction of death (Nusseibeh, 2017, p. 66), and it also appeared in the study (Al-Qiq, 2016). While the study (Al-Kayed, 1995), and the study (Odeh, 2013) found that there is a medium level of death anxiety among the individuals of the studies samples, as it differs from the study (Doha, 2015) which concluded that the level of death anxiety among the elderly was low, as well as a study. (Mahmoud, 2015), as it differs with the studies that indicated that there is no relationship between death anxiety and the age of the sample, such as the Study of Templer \& Lester (1972) and the study (Abd al-Khaliq, 1987), as these studies indicate that more focus should be placed on The causes of increased 
death anxiety among the elderly instead of focusing on the age variable, that is, the factors and causes that underlie the increase in death anxiety in them. The results of the current research also showed that the relationship between feelings of psychological loneliness and death anxiety is a positive correlation with significant significance at the level of (0.05) and for all dimensions A measure of psychological unity (social impotence, loss of familiarity, feeling of rejection), and these results can be interpreted as a normal matter for the individual who suffers from the negative effects of feeling of psychological loneliness, especially since the older individuals age, they attach greater importance to the psychological and emotional aspects of Alula Social Qat, in addition to the fact that they have undergone profound changes and are facing great challenges, this contributes to their suffering in several psychological aspects, including feelings of psychological loneliness and anxiety of death.

This result is consistent with the study (Gerino, et al, 2017), which indicated that feeling lonely negatively affects the quality of psychological and physical life, and that the elderly who suffer from psychological loneliness have lower levels of mental health and also the ability to withstand stress and stress, And they show anxiety and depression, as well as with the studies reported by Al-Shaba 2006, by researchers (Sirmat, Schmidt, and Wood, 1977), and a study (Perelman, 1978) who found a positive relationship between psychological loneliness and a number of features, including anxiety and unhappiness.

And it agrees with the study of Ernst and Cacioppo (1999), and the study (Hawkley, 2004) who found that psychological loneliness negatively affects self-esteem, optimism and communication with others and leads to the individual feeling shyness and pathological anxiety. 2014) indicates that feelings of psychological loneliness and isolation are often mixed with anxiety and uselessness, and they often when talking about their feelings mention the anxiety associated with this unit, and in a study (Zebhauser et al, 2014), it was found that elderly people who feel lonely have a high level of anxiety More than the elderly who do not feel lonely.

This is what was confirmed by both (Lester, et al, 2007), in their research that the degree of death anxiety is affected by two main factors: the mental health status that the individual enjoys in general. Death anxiety, and the second factor: life experiences to which the individual is exposed related to the issue of death (Lester, et al, 2007, 262).

In the study (Shahidi, 2013) it was shown that individuals who suffer from psychological loneliness do not have the desire or motivation to develop their personal skills, abilities and aspirations or to activate their lifestyle positively (Shahidi, 2013,74))

In a study (mock, 2017), it was found that there is a correlation between psychological loneliness and depression in the elderly at a level of (0.01). It was also found that the sample members suffer from psychological loneliness and depression. (Mock, 104, 2017), and also in the study (Hamada, 2003) there was a direct correlation between the psychological and neurotic loneliness of retirees, and among the neurotic symptoms that they suffer from anxiety, and they have disturbing dreams, their pain worries them, and they suffer from anxiety about their health ( Hamada, 113, 2003)

It was also found that the dimensions of psychological loneliness (social disability, loss of familiarity, feeling rejected) contribute by $(15.1 \%)$ to the variance in death anxiety of the research sample, which is statistically significant at the level of (0.05).

Recommendations:

1. Families care about the elderly and take good care of them, communicate with them and share responsibility with them, and emphasize the importance of their roles and the importance of their presence in the life of their families.

2. Government agencies and civil society institutions carry out their duties towards the elderly to reduce their suffering and provide the atmosphere that relieves their feelings of psychological loneliness and death anxiety, and the need to support and support them.

3. Activating the role of universities and health institutions in providing counseling and psychological treatment to members of society, including the elderly, to alleviate their suffering and treat their psychological problems.

The proposals:

1- Conducting a study of the effect of counseling programs in reducing psychological loneliness and death anxiety in the elderly.

2- Conducting studies to identify the relationship between psychological unit and other variables in the elderly

3. Conducting other studies on the elderly trying to identify the demographic variables that were not studied in the current research (marital status, housing, chronic diseases, monthly income, educational attainment)

Sources:

1. Iman, Ben Laetrash (2015) The level of psychological loneliness among a sample of elderly people, Algeria, Mohamed Bou Diaf University, Master Thesis.

2. Hamadeh, Muhammad Ahmad (2003): A study of some factors related to the feeling of psychological loneliness among retirees, Gaza, Islamic University, MA thesis. 
3. Zotout Ramadan, and Qureshi Abdel Karim (2013). Quality of life among chronic patients and its relationship to some variables, Algeria, Journal of Human and Social Sciences, Issue 11

4. Saadi, Rima, and Bekdash, Raneem (2017) The level of psychological loneliness among the elderly residing in social care homes in the cities of Lattakia and Tartous, Syria, Tishreen University Journal, Volume 39, Issue 2.

5. Al-Shaboon, Dania (2006), Psychological Security and its Relationship with Psychological Unity, Unpublished MA Thesis, Syria, Damascus University.

6. Souria, Bardad (2017), The Relationship of Psychological Unit with Depression in Elderly People, Algeria, Abdel Hamid Ben Badis University, MA Thesis.

7. Ghanem, Muhammad Hassan (2002). Perceived social support and its relationship to feelings of psychological loneliness and depression among the elderly and elderly residing in shelters and natural families, Arab studies in psychology, Dargrib for printing, publishing and distribution, Cairo, Volume 1 , Issue 3.

8. Fromm, Eric (2009). Escape from Freedom, translated by Mahmoud Munqeth, Damascus, General Book Authority.

9. Freud, Sigmund (1981) Ideas for the Times of War and Death, translated by Samir Karam, Beirut, Dar Al Tali'a for Printing and Publishing, 2nd Edition.

10. Al-Qiq, Areej Khalil Muhammad (2016), Anxiety of death and its relationship to mental health among a sample of elderly people, College of Education, Gaza University, MA Thesis.

11. Mahmoud, Doha, Adel (2015). The anxiety of death among the elderly and its relationship to satisfaction with the goals of life, Baghdad, Al-Ostad Magazine, Issue 215.

12. Mukhtar, Wafra, and Shaanabi, Noureddine (2017). Death anxiety and its relationship to some variables, Algeria, Al-Riwaq Magazine, Issue (9).

13. Maamriya, Bashir, and Khazar, Abdel-Hamid (2009). Physical and Psychological Disorders in the Elderly, Journal of the Arab Psychological Science Network, Issue 23.

14. Nusseibeh, Ashour (2017). Death anxiety in the elderly, its manifestations and effects, Al-Arabi University, Algeria, MA Thesis.

15. Becker, Ernest (1973). The Denial of Death. New York: Simon \& Schuster.

16. Cronbach , L .J . ( 1970 ).Essentials of Psychological testing, New york : Harper and Row publishers.

17. Ditommaso ,E, \& Spinner ,B.(1993)The development and initial validation of the social and emotional loneliness scale for adults (SELSA).Personality and Individual Differences, 14(1).

18. DuBois ,Philip H ,(1962).Educational Research in Ongoing Situations

19. Eurostat (2015a). People in the EU - Statistics on Demographic Changes.

20. Gerino, Eva, Luca Rollè, Cristina Sechi ,PieraBrustia (2017).Loneliness, Resilience, Mental Health, and Quality of Life in Old Age: A Structural Equation Model,https://www.frontiersin.org/articles

21. Lester,D ,Templer,D, Ahmed Abdel-Khalek. (2007). ACross-Cultural Comparison of Death Anxiety: A Brief Note. Omega: Journal of Death and Dying, (54).

22. Lim, M. H., Rodebaugh, T. L., Zyphur, M.J., \& Gleeson, J. F. (2016). Loneliness over time: The crucial role of social anxiety. Journal of Abnormal Psychology, 125(5).

23. New Economics Foundation \&The Co-Op 2017. The cost of loneliness to UK employers. Manchester: The Co-Op .

24. Nunnally, J.C. (1970) Introduction to psychological measurement, New York: McGraw Hill company.

25. Nunnally, J.C. (1978): Psychometric Theory. New York: McGraw Hill company

26. Rogers, C. (1980) A way of being. New York :Houghton Mifflin Company

27. Rokach , Ami (1988) : The Experience of Loneliness :Atri-level Model, The Journal of Psychology,Vol.122, No .6.

28. Peplau L \& Perlman D (1982). Perspectives on loneliness. In: Peplau L \& Perlman D (eds). Loneliness: A sourcebook of current theory, research, and therapy. New York: Wiley.

29. Shahidi, Mehrdad (2013),Loneliness as a Predictor of Mental Health Components, Thesis for: Master of Arts in Child and Youth Study.

30. Templer, D.I., (1970). The construction and validation of a death anxiety scale, Journal of General psychology .

31. Templer, D.I. , Barthlow, V.L. , Halcomb, P.H. , Ruff, C.F. ( 1979 ) : The death anxiety of convicted felons, corrective and social psychiatry and Journal of behavior technology, methods and therapy .

32. www.who.int(2017)/ar/news-room/fact-sheets/detail/mental-health-of-older-adults .

33. Weiss ,R ,(1987): Reflection the present state of loneliness research ,Journal of Personality and social psychology, Vol.2. 
34. Zebhauser, A.; Hofmann-Xu, L.; Baumert, J. Häfner, S. Lacruz, M.E.(2014) How Much Does it Hurt to be Lonely? Mental and Physical Differences between Older Men and Women in the KORA-Age Study. Int. J. Geriatr. Psychiatry , 29. 